\title{
ASPECTOS DO COMÉRCIO DOS DOMÍNIOS PORTUGUESES NO PERÍODO DE 1808 A 1821.
}

A história do Império português, no que diz respeito à organização e às relações comerciais, oferece, no período de 1808 a 1821, aspectos interessantes. Aproveitando documentos existentes no Arquivo Nacional (Rio de Janeiro), principalmente documentos sôbre o movimento do comércio marítimo, pudemos fazer as observações que apresentamos neste trabalho.

Relativamente à sua organização econômica, o domínio colonial português, nessa época, viu surgiu uma transformação nos princípios que o regiam, determinada pelas circunstâncias novas em que se via o govêrno.

Foi uma transformação gradual, mas relativamente rápida, que atingiu o sistema do exclusivismo comercial.

O primeiro passo para essa modificação foi dado pela abertura dos portos brasileiros ao comércio das nações amigas. Todos conhecemos bem as circunstâncias que determinaram a adoção dessa medida, decidida por Carta Régia de 28 de janeiro de 1808. Não insistiremos sôbre elas. A abertura dos portos colocava o Brasil em situação de igualdade com a Metrópole no campo do comércio, e em situação privilegiada em relação aos outros domínios. Portugal deixava de ser o intermediário entre o Brasil e os Estados estrangeiros, que poderiam, de então em diante, comerciar livremente nos portos brasileiros, trazendo para cá tôdas as mercadorias que desejassem, e levando todos os produtos de seu interêsse, exceto pau brasil. A medida, cujo valor para o Brasil não é preciso encarecer, provocou novas reformas. $\mathrm{Na}$ Carta Régia de 28 de janeiro, mercadorias estrangeiras e portuguêsas eram postas no mesmo pé de igualdade quanto aos direitos que deveriam pagar, com prejuízo natural para o comércio de Portugal. Por causa da situação difícil da Metrópole, criada pela guerra, e por causa da inferioridade da indústria e da organização comercial, as praças portuguêsas não poderiam concorrer com as estrangeiras: perderiam logo a supremacia no mercado colonial. Para remediar o mal, medidas foram tomadas: diminuição dos direitos das mercado- 
rias (fazendas e molhados) pertencentes a vassalos portuguêses, e transportadas para o Brasil em navios portuguêses, pelo decreto de 11 de junho de 1808; isenção de direitos de entrada para as mercadorias fabricadas em Portugal (fazendas e molhados), segundo Ordem e Decreto de 13 e 20 de outubro de 1808. Vemos então uma preocupação nova sobrepujar considerações puramente fiscais: o desêjo de defender a indústria e proteger os interêsses dos negociantes portuguêses, interêsses que eram, na realidade, os do próprio Estado.

Mas não ficou nisso a transformação: um novo passo para a frente foi dado com a assinatura do tratado de comércio com a Grã-Bretanha, em fevereiro de 1810. Uma permissão ampla para os inglêses comerciarem nos domínios portuguêses era dada pelo acôrdo. Em todos os domínios êles passaram a ser admitidos em condições favoráveis. Duas restrições apenas: no comércio nos portos e mares da Asia e na Costa Oriental da Africa, e no comércio dos produtos tipicamente coloniais. Nos portos da Ásia e da Africa Oriental, o comércio e a navegação dos inglêses seriam permitidos no mesmo grau em que haviam sido efetuados até então. O govêrno português tomava precauções para assegurar para seus 'súớitos o comércio asiático, e foi mesmo êste um ponto a respeito do qual os encarregados portuguêses na negociação do acôrdo mostraram-se firmes. O artigo 21 do tratado cuidou da defesa do comércio dos produtos coloniais. Para salvaguardar o comércio dos produtos das fndias Orientais Portuguêsas e do Brasil, que existiam também nas colônias britânicas, e impedir que os comerciantes lusos fôssem dêle excluídos, foi tomada a decisão de impor direitos proibitivos sôbre

"todos os artigos conhecidos pelo nome de gêneros das Indias Orientais e de produtos das Indias Ocidentais Britânicas".

A proibição era mantida, dizia o tratado, por causa do mesmo princípio que impedia a introdução de artigos da mesma natureza, oriundos de lugares não inglêses, nos domínios britânicos. Esses produtos poderiam ser admitidos sòmente para reexportação.

Permitindo, assim, o comércio dos inglêses, o tratado de 1810 abria para os domínios portuguêses novas correntes de trocas, e alargava o sistema comercial em que viviam.

$\mathrm{O}$ antigo sistema de comércio, atingido por essa concessão feita aos inglêses, foi depois amplamente reformado. O Alvará de 4 de fevereiro de 1811 ampliou a liberdade de comércio con- 
cedida ao Brasil em 1808, estendendo-a a todo o Império: Antes daquela data, porém, medidas parciais indicavam a mudança na atitude do govêrno português no que dizia respeito aos interêsses econômicos dos domínios. Assim, o decreto de 13 de maio de 1810 (1) e as cartas régias de 30 do mesmo mês e ano e de 2 de junho de 1810 permitiam e regulavam o comércio direto entre Macau e o Brasil: graça especialmente concedida à Câmara de Macau como recompensa pela fidelidade da cidade ao Príncipe'Regente, e pela luta vitoriosa contra os piratas chineses que infestavam os mares vizinhos. As citadas ordens permitiam o comércio direto entre Macau e o Brasil, sem a escala de obrigação em Goa, e isentavam de direitos de entrada nos portos brasileiros os gêneros e mercadorias da China, desde que fôssem propriedade de vassalos portuguêses daquele pôrto asiático, e fôssem transportados em embarcações portuguêsas construídas nos estaleiros lusitanos da Ásia.

Mais interessante do que esta, porque não foi dada como recompensa mas sim como meio de solucionar problemas locais, foi a concessão, pelo alvará de 25 de outubro de 1810 (2), da liberdade de comércio às Ilhas dos Açores, separadas até então umas das outras por regulamentos antiquaados de comércio. Aqui já podemos perceber a mudança de orientação do govêrno português, relativamente à maneira de considerar as colônias. Alguns trechos do alvará nos esclarecerão:

... "E não devendo os habitantes das diferentes Ilhas, que formão a Provincia, Governo, e Capitania das Ilhas dos Açores, considerarem-se como Estrangeiros, huns a respeito dos outros, mas sim como compatriotas, e Nacionais, egualmente protegidos pelas Minhas Paternaes, e Providentes Leis, ehabelitados para obterem da Minha Real Benevolencia todos os beneficios tendentes apromover a Fe. licidade de todos e de cada un delles; Determino"...

E mais adiante, continua o alvará, tratando dos direitos que deveriam pagar os vinhos exportados,

..."pagando os direitos de sahida, alli existentes, emquanto senão publicar a nova Pauta ou Tarifa a que Tenho mandado proceder, em beneficio do Commercio, Agricultura e Industria Nacional, Estabelecida sobre as bazes de bem entendida liberdade, protecção, esegurança sobre que deve ser fundada a Legislação do Commercio".

(1). - Arquivo Nacional. Coleção 48, livro I, f. 156 verso.

(2). - Arquivo Nacional. Coleção 48, livro I, f. 166 verso. 
E o alvará continua concedendo às Ilhas a liberdade de comerciarem umas com as outras, e estabelecendo algumas regras de comércio. Analisando-o, encontramos várias novidades: $\left.1^{\circ}\right)$. - a concessão foi feita, como se vê na transcrição acima, porque os habitantes dos Açores eram todos membros de uma mesma Nação, e porque mereciam, como tais, a atenção e a benevolência de Sua Alteza, o Príncipe Regente; $2^{\circ}$ ). - a circulação dos produtos entre as Ilhas tornava-se livre: não havia direitos a pagar; os únicos que existiam seriam pagos pelos produtos de exportação para fora das Ilhas e de importação estrangeira; $3 .^{\circ}$ ). - um cuidado especial foi tomado para proteger e encorajar a indústria manufatureira das Ilhas, sendo isentos de direitos de saída os produtos dessa indústria exportados para o estrangeiro. Essas resoluções representam, realmente, uma coisa nova no quadro da política colonial portuguêsa. $\mathrm{E}$, coisa nova também, a decisão tomada pelo alvará de 26 de outubro de 1810 de formar, em Ponta Delgada, na Ilha de São Miguel, do mesmo Arquipélago dos Açores, um depósito para recepção de produtos de comércio, nacionais e estrangeiros, que os negociantes quisessem ali colocar para facilitar suas transações, foi dada como um meio de "promover o aumento e prosperidade do comércio". 1811 (3).

A evolução continuou com o alvará de 4 de fevereiro de

Vale a pena conhecermos a primeira parte, embora um pouco longa, dêsse alvará: ela indica-nos os novos princípios da política portuguêsa, e nos dá algumas das razões das transformações introduzidas.

..."Para que todos os Vassallos, de todos os Dominios da Monarchia Portugueza hajão de gozar, sem distinção, de todas as vantagens, que tenho facilitado por uma bem entendida liberdade de Commercio: Determinei extendelas, e ampliallas a beneficio do Commercio assim aos meus Dominios na Costa de Africa Occidental, e Ilhas Adjacentes, como em todos os mais Estados alem do Cabo da Boa Esperança, para que, por este vasto e geral systema de Commercio, se reproduzão novos meios de corresponden. cia, e relação entre os Meus Vassalos, rezidentes nos importantes, e preciozos Dominios que Possuo nas mais fe. lizes e ricas paragens do Globo, e venha a formar-se um novo nexo, que ligando as distantes possessões, sugeitas ao Meu Imperio, pelo desenvolvimento de novas especulações, e relações Commerciaes, hajão não somente de fa-

(3). - Arquivo Nacional. Coleção 48, livro I, fs. 170-175. 
cilitar aos Vassalos grandissimos interesses, mas deva tambem concorrer para consolidar a força, a energia, e o poder do Corpo do Estado".

$E$, falando, então, da inaplicabilidade de decretos e alvarás anteriores, relativos ao comércio de Goa, diante das circunstâncias atuais do Estado, prossegue textualmente:

..."nem correspondem (tais decretos e alvarás) aos grandes fins, que Me tenho proposto pela organização de hum Plano e Systema geral de Commercio, que haja de abraçar todos os Meus Reinos, e Dominios nas quatro par tes do Mundo, e soltar as prizóes que impedião e fechavão parte dos Portos dos Meus Estados ao Commercio directo com outros Portos dos Meus proprios Dominios: E Considerando por outra parte, que a pozição geografica do Brasil hé por si mesma a mais favoravel e apropriada, para se construir o Emporio do Commercio de Entreposto entre a Europa, e Asia Resolvi facilitar por meio das amplas concessões, que por este Alvará liberalizo aos Meus fieis Vassallos, o Commercio e Navegação directa nos $\mathrm{Ma-}$ res da India, China, Enseadas, Rios, Ilhas e Portos: assirm Nacionaes, como Estrangeiros alem do Cabo da Boa Espe: rança, como tambem nos Portos de. Portugal, Brasil, Ilhas dos Açores, Madeira, Ilhas de Cabo Verde, Portos das Costas de Africa Occidental, e Ilhas Adjacentes, pertencentes a Minha Real Coroa: Abolindo todas as restricções, que por muitos anos obstruirāo os Canaes da prosperidade, opulencia e poder, que em outros tempos elevarão a $\mathrm{Na}$ ção Portuguesa ao maior auge de Gloria, de Esplendor e de Riqueza, que passando depois ao poder de outras Naçõe.; industriozas, lhes facilitarão os meios de Força, e Grandeza, com que, sustentando asua independencia, se fizerão poderozas e respeitaveis: Portanto: Revogando as Dispozições do citado alvará... Sou servido Determinar o seguinte"...

E segue-se a regulamentação do comércio para as Índias, Africa Oriental e Ocidental, segundo novos princípios.

O govêrno português reconhecia, nesse alvará, os erros da sua legislação colonial, e tomava corajosamente um novo rumo. Cremos que a medida, reflexo das novas doutrinas coloniais que apareciam, resultado das reclamações contra abusos e práticas antiqüadas e prejudiciais, foi determinada pelas circunstâncias novas do Império, e mesmo pelo desêjo de contrabalançar, de certa maneira, a influência que os comerciantes inglêses adquiririam nos domínios portuguêses, graças ao tratado de comércio impôsto pelos acontecimentos. 
Não devemos crer, contudo, que a liberdade de comércio concedida pela determinação citada tenha sido completa, ou baseada em princípios muito liberais. $\mathrm{Na}$ regulamentação contida no alvará de 4 de fevereiro de 1811, aparece, como, aliás, nos alvarás anteriores relativos às Ilhas dos Açores e nos regulamentos referentes ao comércio e indústria do Brasil, a preocupação de proteger o comércio português, a marinha mercante, sobretudo a marinha da carreira das fndias, e de favorecer a produção industrial nacional. A política portuguêsa, no período, liberalizando embora concessões, quebrando o rígido exclusivismo colonial, apresenta-se profundamente protecionista. Para dar vida ao comércio, à indústria e à marinha, estagnados ou decadentes, incapazes de enfrentar uma concorrência estrangeira intensa, recorreu-se ao protecionismo. $O$ govêrno português, aliás, colocava-se dentro da corrente protecionista, geralmente aceita na época. Por isso, vemos nos alvarás citados e noutros regulamentos posteriores, o cuidado em dar aos vassalos portuguêses vantagens especiais no comércio do Império, o cuidado em estabelecer direitos alfandegários que protegessem sua atividade, em impor medidas que favorecessem a marinha nacional, ou que concorressem para o desenvolvimento da indústria.

Regulamentos posteriores cuidaram ainda da questão do comércio das colônias, tratando de questões variadas; não nos deteremos, contudo, no seu estudo, interessando-nos apenas conhecer as condições gerais do comércio. Queremos notar, sòmente, que, em 1816, foi organizada uma comissão que deveria cuidar da regulamentação geral das relações comerciais entre os Domínios da Corôa Portuguêsa, de acôrdo com os novos princípios estabelecidos.

Voltando, então, nossas vistas para o problema das relações comerciais entre os vários domínios, deparamos também com questões interessantes. Nossas observações neste particular são tôdas baseadas nos "Mapas de importação e exportação", existentes no Arquivo Nacional (4).

O primeiro fato que temos de constatar, ao estudar o comércio dos domínios portuguêses, no período 1808-1821, é a

(4). - Várias ordens, avisos e provisões determinavam fôssem enviados, pelos funcionários encarregados, à Côrte do Río de Janeiro, os dados referentes ao movimento dos portos dos vários dominios, a partir de 1808 'para alguns, e de 1809 para outros. Estabelecia-se que fôssem: organizados mapas de importação e exportação, segundo fórmula fornecida pelo govêrno: isto, para evitar falhas e para obter, segundo era explicado, o maior número possível de informações sôbre o assunto e para conhecer exatamłente o 'desenvolvimento do comércio dos domínios. 
mudança do centro comercial de Portugal para o Brasil. A mudança da Côrte, sòmente, seria motivo suficiente para que isto acontecesse. Mas a causa da mudança da Côrte foi também a causa da queda do comércio dos portos portuguêses: a ocupação francesa em Portugal, e depois a guerra com a França provocaram um arrefecimento do seu movimento comercial . Entre 1808 e 1814, mais ou menos, Lisboa, o antigo centro comerciante do Império português, viu decair muito o volume dos seus negócios, e deslocar-se para o Brasil o eixo do comércio do Estado português.

Passado o período de crise, com o término da guerra, Lisboa procurou reaver sua antiga posição: entre 1815 a 1821, notamos um crescimento sensível das suas relações comerciais com os domínios, com o aumento de importações e exportações. Mas Lisboa não voltou a ocupar o lugar primitivo. Sua superioridade absoluta no comércio com vários domínios não 'foi reconquistada.

O Rio de Janeiro herdou de Lisboa o lugar de pôrto principal do Império português, o que, aliás, é natural, não só por estar numa posição propícia, como por ter-se tormado a sede da 'monarquia.

Um segundo fato que não podemos deixar de considerar aqui é a possibilidade de comércio direto com os estrangeiros. Os colonos puderam receber, sem intermediários, produtos não portuguêses, graças às medidas a que já nos referimos. Nesse comércio, salvo em algumas pequenas regiões, como as Ilhas de Cabo Verde (5), por exemplo, a superioridade coube aos inglêses, dotados das vantagens que lhes concedeu o tratado de 1810. Até 1814, ao lado dos britânicos, figuravam apenas comerciantes das Américas - dos Estados Unidos, de Montevidéu, de Buenos Aires, de Havana. Depois da derrota de Napoleão, outros países passaram a figurar, por seus comerciantes, nos portos portuguêsas das colônias. Mas a posição da Inglaterra não sofria concorrência, e o volume do seu comércio foi sempre muito superior ao das outras nações. Esta nova situação veio trazer aos colonos maior possibilidade de confôrto, pelo normal abaixamento dos preços das mercadorias trazidas sem intermediários, em maiores quantidades do que anteriormente, e tendo diminuídos os direitos de entrada. Também o govêrno deve ter lucrado: a possibilidade de entrada ilimitada e legal de mer-

(5). - Nas Ihas de Cabo Verde predominavam os norte-americanos. $O$ autor da "Memoria ou descripção physico-politica das Ilhas de Cabo Verde"', 1810, (A. N., cx. 644, pac. 3 ), diz que $3 / 4$ do comércio dessa regiäo era feito por navios americanos. 
cadorias deve ter diminuído o contrabando; e o crescimento do movimento nos portos deve ter aumentado as rendas reais.

Estabelecidos êsses pontos, passemos à consideração do movimento comercial das várias regiões.

Comecemos pela Ásia e pela Africa Oriental que formavam uma unidade comercial. Goa era o centro do comércio: sôbre êste pôrto, muito especialmente, legislava o alvará de 4 de fevereiro de 1811. O comércio de Goa, no período que nos interessa, seguiu os rumos já anteriormente estabelecidos. Foi êle o que menos sofreu em sua direção com as transformações ocorridas no Império português. Goa fazia um 'comércio que chamaremos local (6), o comércio indiano, e com o resultado das transações efetuadas comerciava com os outros pontos do Império português. Sendo êste um comércio geralmente reservado pelas nações que possuiam interêsses na Índia, e pelo próprio Portugal, saindo da Asia, Goa só comerciava com portos lusitanos. Constituindo o material do seu comércio de exportação, fazendas e gêneros das Indias Orientais, supria-se o pôrto dos elementos que lhe faltavam pelas trocas com outros centros asiáticos, de possessão estrangeira ou hindus. Comerciava com Macau, de onde lhe vinham os gêneros da China e das Ilhas da Oceania. Comerciava com portos da Índia, de onde recebia os outros gêneros da sua exportação. Dio e Damão, os dois outros centros portuguêses, mandavam para Goa os produtos do seu comércio, sem manter relações diretas com o Ocidente. Dos portos da fndia coloca-se em primeiro lugar como exportador para Goa, Surate; sòmente em 1815, cedeu êste pôrto o lugar a Bombaim. Nos outros anos, tendo como principal produto as fazendas, as vendas feitas a Goa por Surate atingiram cifras muito mais elevadas que as feitas pelos outros portos - Bombaim, Balagate, Ragiapur, etc. Do Ocidente e de Moçambique, recebia Goa o material para seu consumo e para as trocas que realizava nas fndias. Além de fazendas, gêneros e miudezas, recebia metal para as suas transações. Assim, do Brasil e de Moçambique, saíam, com os vários produtos, patacas e ouro e prata. Vejamos alguns números: em 1810, figuram como importadas da América Portuguêsa 21.900 patacas, correspondendo a 105.102 xerafins (dinheiro indiano); em 1816, saíram do Brasil para Goa 62.367 patacas. De Moçambique, além de patacas, saíam ouro em pó e prata velha, marcos de ouro e prata. Esta necessidade de enviar o metal precioso, em moeda ou não, para as compras na Ásia, fazia que alguns eco-

(6). - Mapas de importação e exportação de Goa, 1808-1821. 
ńomistas condenassem o comércio asiático como não proveitoso, e a polêmica em tôrno do assunto, na Europa, durou muito tempo. Os produtos recebidos do Ocidente, por Goa, serviam para sua exportação para os portos vizinhos da fndia: o maior importador de Goa foi, no período, Bombaim.

Interessante será fixarmos nossa atenção na corrente de comércio entre Goa e Moçambique. Recebendo panos, sobretudo os chamados panos de cafre, e outros gêneros, como cêra, especiarias, louça da China, etc., Moçambique enviava em troca, além do metal, escravos, marfim, comestíveis. Diz um relatório da época, existente no Arquivo Nacional (7), que Moçambique vivia dêsse comércio. Tôda a sua renda vinha dos direitos de alfândega provenientes do comércio com Goa. O pano da India - fato cafreal, como o chama o autor do relato - servia de moeda: com êle pagavam-se as fôlhas eclesiástica, civil e militar de todo o continente africano. Sòmente em Moçambique êle não valia como moeda; aqui corria apenas a moeda metálica. Da entrada dessa fazenda dependia todo o comércio africano de Moçambique. $\mathrm{E}$ como estava em decadência o comércio com a India, no momento, lembrava o autor da informação que se cuidasse de reerguê-lo para melhorar a vida da colônia africana.

Das colônias orientais, merece também nossa atenção Macau: êste pôrto da China recebia produtos de Lisboa, Rio de Janeiro, dos portos da fndia e das Ilhas da Oceania, Timor, Filipinas. Os produtos dêsse comércio eram geralmente enviados para Goa, e daqui partiam para o Brasil e Portugal; havia também ligação direta com o Brasil, permitida pelos atos já citados.

Consideremos agora o caso do Brasil: não poderemos, dadas as insuficiências dos documentos consultados, dar uma idéia completa do seu comércio (8). Podemos, contudo, fazer algumas observações interessantes, que poderão servir de ponto de partida para futuros estudos. Logo no início do período, a abertura dos portos decidiu a orientação do comércio brasileiro. Transformado em intermediário entre o estrangeiro e os domínios, pelas circunstâncias que já apontamos, o Brasil conservou essa posição mesmo depois de 1811. Dêsse modo, graças à ne-

(7). - Ofício de Antônio José de Carvalho a Antônio Manuel de Melo, expondo o estado em que se acha Moçambique, 1808. (A. N., ex. 658, pac. 2b 23).

(8). - A deficiência da documentação reférente ao Brasil foi contstatada na época mesmo pelo oficial José Antônio de Mira, encarregado de fazer resumos dos mapas chegados. Diz êle em todos os resumos, feitos, aliás, sòmente até 1814, que as observaçōes relativas ao comércio brasileiro ficavam prejudicadas porque havia falta de dados sôbre capitanias possuidoras de comércio muito de. senvolvido, como Bahia, Maranhão e Pará. 
cessidade de fornecer a outras regiões, a importação que fazia de produtos estrangeiros (de origem inglêsa na grande maioria) era muito maior do que a necessária para o seu próprio consumo: da reexportação do excedente fazia um dos ramos do seu comércio, e tirava grande rendimento.

Merece que lhe dediquemos nossa atenção, o comércio com a Grã-Bretanha. Já com a abertura dos portos, invadiram os produtos inglêses os centros brasileiros. Sua posição consolidouse depois do tratado de 1810 . Não possuimos dados relativos ao principal pôrto dêsse comércio, o Rio de Janeiro (9): podemos perceber o valor das transações pela grande massa de produtos de origem inglêsa que êle reexportava para outros pontos do Brasil, da Africa e da Ásia. Uma indicação sôbre o volume das importações britânicas pode ser-nos dada pelos números referentes a Pernambuco (10). Em 1810, entraram ali, vindas da Grã-Bretanha, mercadọias - fazendas, gêneros sêcos e molhados, víveres, ferragens - no valor de 853:216\$000, quase metade do valor total do comércio de importação, que orçou em .... 1.938:135\$640 (total onde está incluído também o valor de todos os escravos importados); em 1812, a importação de produtos da Grã-Bretanha foi de 775:070\$000; em 1815, último ano para o qual temos dados de Pernambuco, o valor dessa importação foi de 595:063\$520 (a diminuição foi devida talvez ao reajustamento de Lisboa como exportador para o Brasil). E' interessante notar também que os inglêses não comerciavam em todos os portos brasileiros: os do Norte parece terem sido todos atingidos. O Ceará (11), por exemplo, tendo ainda um comércio muito reduzido, recebia já mercadorias da Inglaterra. Mas os inglêses não se interessaram muito pelos portos do Sul. Santos e Rio Grande sòmente num ou noutro ano receberam mercadorias diretamente da Grã-Bretanha. As mercadorias vindas desta região eram recebidas pelos portos do Sul por intermédio do Rio de Janeiro, da Bahia ou de Pernambuco. O Rio de Janeiro era o grande centro reexportador.

A exportação para a Grã-Bretanha fazia-se também em grande escala. Infelizmente possuímos dados a êsse respeito sòmente com referência a Pernambuco. Em 1810, a exportação para a Grã-Bretanha, por êsse pôrto, foi de 1.460:461\$455,

\footnotetext{
(9). - E' também lamentável que não existam mapas referentes ao Rio de Janeiro; podemos avaliar a importância do seu movimento comercial pelas informações que trazem os mapals relativos a outros lugares, mas isto não é suficiente para termos uma indicação exata sôbre as relações comerciais do prin. cipal pôrto português na época.

(10). - Mapas de importação e exportação de Pernambuco, 1808-1815.

(11). - Mapas de importação e exportação do Ceará, 1809-1810.
} 
num total de 1.947:964\$430, para as exportações; em 1812, foi de $881: 488 \$ 750$, sendo o valor total de 1.695:391\$840; em 1815, foi de 1.088:942\$700, num total de 3.305:566\$740. O comércio de Pernambuco com a Grã-Bretanha foi-lhe sempre favorável: a exportação pernambucana foi, de 1810 a 1815 , sempre superior à importação. O grosso da exportação era constituído por algodão: no total citado de 1810, 1.222:235\$000 entraram pela exportação de algodão; em 1812, 856:430\$000 procederam da venda do algodão aos inglêses; e em 1815, 937:573\$000 correspondem ao valor do algodão levado para a Grã-Bretanha. Do Ceará, o único produto de exportação para a Grã-Bretanha era o algodão. Colocava-se, em Pernambuco, depois do algodão, o açúcar; couros, carnes, sebos e outros produtos brasileiros entravam na lista. Os produtos de portos como Santos e Rio Grande eram transferidos para a Grã-Bretanha por meio dos portos intermediários.

Depois a Grã-Bretanha, colocavam-se, como maior comerciante nas listas dos portos brasileiros, os Estados Unidos. Havana, Montevidéu e Buenos Aires faziam algum comércio. Depois de terminada a guerra na Europa, apareceram também comerciantes de outros países europeus: da Espanha, da Itália, da França, da Holanda, etc.

A estas correntes do comércio brasileiro, devemos acrescentar as correntes que se dirigiam para os outros pontos do Estado português. Lisboa e Pôrto continuaram a manter relações com os portos do Brasil, mesmo no período mais agudo da crise que os atingiu. O movimento era intenso entre o Brasil e os portos portuguêses da Asia e da Africa.

Sôbre o comércio de cabotagem cabem algumas observações interessantes. O Rio de Janeiro era o grande centro de comércio para os portos do Sul; com o Norte, suas relações eram muito menores. Algumas informações de ordem particular podemos ter sôbre alguns pontos. Pernambuco, por exemplo, comerciando com a Bahia, pouca coisa lhe exportava em mercadoria. Seguiam seus navios para lá, geralmente levando lastro de areia e transportando dinheiro para a aquisição de farinha de pau, que a Bahia lhe fornecia em grande quantidade. O mesmo acontecia com os navios que iam de Pernambuco para o Rio Grande do Sul: levavam dinheiro para a compra de couros e outros produtos da indústria pecuária. Santos, por sua vez, fazia um comércio mais ou menos intenso com os portos de Pernambuco para o Sul. Seu principal produto de exportação era o 'açúcar, e, entre as mercadorias de importação, ocupava lugar de 
destaque o sal. O pôrto de Rio Grande (12) dividia a sua exportação entre produtos da pecuária e trigo, em grão ou farinha. $\mathrm{Na}$ exportação para o Rio de Janeiro, em 1809, num total de ....... $355: 219 \$ 280,108: 985 \$ 500$ pertenciam à carne sêca e 102:701\$200, ao trigo. Em 1814, sua exportação de trigo, sòmente para o Rio de Janeiro foi de 242.497 alqueires.

Essas são algumas observações que nos permitem fazer os dados existentes sôbre o comércio brasileiro.

Um comércio especial ocupava lugar destacado nas relações comerciais brasileiras. Trata-se do comércio de escravos, que constituia atividade importante no Império português. Deixamos para mencioná-lo separadamente, porque desejamos apresentá-lo no conjunto do comércio dos domínios portuguêses. Apesar das novas correntes abolicionistas e da pressão da Grã-Bretanha, êle continuou a ser feito neste período, exceto em pequena área, onde havia sido ajustada a sua abolição. Dois centros havia de tráfico de escravos, como sabemos: a Costa Ocidental da Africa, o principal, e Moçambique. De Moçambique saíam escravos para Goa, como se vê nos mapas relativos a êste pôrto. Também para o Brasil vinham escravos de lá; não podemos, contudo, avaliar a sua quantidade, pela inexistência de dados relativos à Bahia e ao Rio de Janeiro, dois grandes portos traficantes. 'O único dado que nos fornece a documentação utilizada, sôbre importação de escravos de Moçambique é o da aquisição ali, de 239 escravos novos, pelo pôrto de Santos, em 1821. A Costa Ocidental da Africa, no entanto, foi a grande fornecedora do Brasil. Benguela, Angola, Mina, Costa de Ajudá, Cabinda, Ilhas de São Tomé e Príncipe forneciam contingentes de escravos. De Benguela, a principal corrente do tráfico dirigia-se para o Rio de Janeiro, para onde vieram, em 1809, 5.129 escravos, e em 1812, 4.345; outras correntes dirigiam-se para Angola, Bahia e Pernambuco. De Loanda, os escravos eram conduzidos para o Rio de Janeiro, Pernambuco e Bahia, para o Maranhão e o Pará - para estas duas regiões, sòmente a lpartir de 1812, e assim mesmo sem freqüência anual. Vejamos alguns números: em 1808, saíram de Angola para o Brasil, 11.072 escravos adultos e 360 crianças; em 1812, o total foi de 10.481 adultos e 223 crianças; em 1816, saíram 14.760 em idade de trabalho, e 244 crianças; e em 1820, 20.052 adultos e 370 crianças deixaram Angola.

Pernambuco comprava escravos ainda em Cabinda, Costa de Ajudá, Bissau e Ilhas de São Tomé e Príncipe; em 1818,

(12). - Mapas de importação e exportação de Rio Grande, 1808 1821. 
1819 e 1820 entraram ali 9.433, 9.009 e 7.696 escravos, respectivamente (13). Bahia fornecia-se mais na Costa da Mina, parecenos, pelas alusões que aparecem de vez em quando. De Mina e Bissau importou escravos também a Guiana, em 1812, 1814 e 1815. De Cabinda vieram os únicos escravos importados diretamente da Africa pelo Rio Grande, em 1814 e 1815: 237 e 30 negros, respectivamente.

Dessas regiões africanas originavam-se as correntes do tráfico. Mas havia outras correntes dentro do Brasil. Da mesma forma que para as mercadorias, os portos importadores brasileiros serviam de redistribuidores para os escravos. Assim, Santos recebia seus escravos - escravos novos - do Rio de Janeiro, da Bahia e, às vêzes, de Pernambuco. O Rio Grande recebia-os - novos e ladinos - dos mesmos lugares. Havia também transporte de escravos, em pequena quantidade, de um para outro pôrto.

Ao mesmo tempo que fornecia escravos, a Costa Ocidental da Africa exportava para o Brasil cêra branca e amarela e marfim; e daqui recebia mercadorias próprias para a compra de escravos e víveres.

Para terminar, falta-nos aludir ao comércio das Iíhas e da Guiana .

Sôbre as Ilhas são também falhos os dados que possuimos. Referem-se êles sòmente às Ilhas de Cabo Verde, pois não aparecem na coleção existente no Arquivo Nacional mapas de Madeira e Ilhas dos Açores. E mesmo sôbre Cabo Verde são incompletas as informações: na Ilha de São Tiago, a principal do Arquipélago, não existia nenhuma escrituração na alfândega, estando tudo, nesse particular, na mais completa anarquia, conforme escrevia o Ouvidor Geral em 1812, tendo sido impossível, portanto, o envio de mapas anteriores a essa data. As Ilhas de Cabo Verde tinham um comércio pouco desenvolvido. Mantinham relações com Portugal, Estados Unidos, Brasil, Costa da Africa, Espanha. Serviam mais para refrescamento dos navios que comerciavam entre a Europa e os portos do Brasil, Africa e Ásia. Recebiam nas suas trocas, víveres e fazendas, e exportavam seus produtos típicos, peles de cabra, couros, vinhos e sal.

A Guiana Francesa ou Colônia de Caiena foi ocupada em 1809 pelos portuguêses e devolvida à França pela convenção luso-francesa de 28 de agôsto de 1817. Enquanto integrada no

(13). - A. N., cx. 449. Escravos importados em Pernambuco nos anos de 1818, 1819 e 1820 . 
Império português, a Guiana recebeu concessões comerciais. A Carta Régia de 6 de junho de 1809, dando notícia ao governador do Pará da nomeação do Intendente da nova colônia (Dr. João Severiano Maciel da Costa), mandava que se estabelecesse

"a livre Exportação e Importação das produçoens de Cayenna, tanto para os Meus Dominios do Brasil, como para Portugal e Inglaterra".

Isto para que os colonos franceses se afeiçoassem ao govêrno português, e se evitassem

"perturbaçoens, que poderião ser fructo da desgraça, em que continuarião, se prezistissem sem Commercio, como actualmente estavão"...

A concessão foi mais tarde ampliada, e a Guiana pôde estender o seu comércio. Êsse comércio (14) era feito com o Brasil, Estados Unidos, Grã-Bretanha, Antilhas e, depois de 1814, com a França também. As principais regiões do Brasil com que mantinha relações eram Pará, Maranhão, Pernambuco e Rio de Janeiro, ocupando o primeiro lugar o Pará. Importava tudo o que é necessário à vida e subsistência, e exportava gêneros da sua produção, ou reexportava mercadorias recebidas das Antilhas ou de outros lugares.

Do que acabamos de expor, podemos deduzir que, entre 1808 e 1821, o Império português, graças às modificações introduzidas no seu arcabouço, conheceu um renascimento do comércio, e que a nova organização e êsse novo desenvolvimento permitiram a satisfação dos interêsses das várias correntes de comércio nele existentes.

\section{OLGA PANTALEÃO}

Professôra da Cadeira de História Moderna e Contemporânea da Faculdade de Filosofia, Ciências e Letras de Marília.

\footnotetext{
(14). - Mapas de importação e exportação de Caiena, 1811-1815. Feitos da meama 'maneira que os outros, êsses mapas contúm informações sôbre as exportações e importações de Caiena, redigidas, às vêzas, em linguagem pitoresca, porque, segundo dizia o Desembargador Intendente, era difícil encontrar ali pessoa que falasse corretamente o português e fôsse capaz de copiar papéis como aquêles.
} 